\title{
A biodiversity evaluation framework for restoration of aquatic macrophyte communities in shallow lakes driven by hydrological process management: case study for the Baiyangdian Lake marsh
}

\author{
Shuhan $\mathrm{LI}^{1}$, Tao Sun ${ }^{1}$, Wei Yang ${ }^{1}$, Baoshan CUI ${ }^{1}$, and Xinan Yin ${ }^{1}$ \\ ${ }^{1}$ Beijing Normal University
}

June 2, 2020

\begin{abstract}
Macrophyte community diversity and composition respond to ecosystem conservation and local environmental factors. In this study, we developed a multidimensional diversity framework for macrophyte communities, including the taxonomic and functional alpha and beta diversity. We used the framework to explore the relationships among water level regimes and these diversity parameters in a case study of China's Baiyangdian Lake. Analysis of indicators of hydrologic alteration divided the water level from 1959 to 2019 into four regimes (dry, <6.42 m; low, 6.42 to $7.23 \mathrm{~m}$; medium, 7.23 to $8.19 \mathrm{~m}$; high, >8.19 m). Alpha and beta diversity were significantly higher in the medium regime than in the low and high regimes. Redundancy analysis indicated that the maximum water depth significantly affected taxonomic alpha diversity, and total nitrogen (TN) and chemical oxygen demand (COD) concentration significantly affected functional alpha diversity, respectively. Mantel tests showed that TN, Secchi depth, and water depth in the high water level regime significantly increased the total beta diversity and turnover components. TN was the main factor that increased total taxonomic beta diversity. Interspecific competition decreased with the decreasing range (variation) of $\mathrm{TN}$ values and differed opposite with the variation of COD values in response to increasing water level, and reached its maximum in the medium regime. Ecosystem stability was promoted by maintaining high species richness and evenness and high differences among communities, and by reducing competition. Based on our results, the water level should be maintained between the medium and high water level regimes to promote restoration of the macrophyte community and improve ecosystem stability.
\end{abstract}

\section{Hosted file}

A biodiversity evaluation framework for restoration of aquatic macrophyte communities in shallow lakes available at https://authorea.com/users/328838/articles/455989-a-biodiversity-evaluationframework-for-restoration-of-aquatic-macrophyte-communities-in-shallow-lakes-driven-byhydrological-process-management-case-study-for-the-baiyangdian-lake-marsh

\section{Hosted file}

Tables.docx available at https://authorea.com/users/328838/articles/455989-a-biodiversityevaluation-framework-for-restoration-of-aquatic-macrophyte-communities-in-shallow-lakesdriven-by-hydrological-process-management-case-study-for-the-baiyangdian-lake-marsh

\section{Hosted file}

Figures.docx available at https://authorea.com/users/328838/articles/455989-a-biodiversityevaluation-framework-for-restoration-of-aquatic-macrophyte-communities-in-shallow-lakesdriven-by-hydrological-process-management-case-study-for-the-baiyangdian-lake-marsh 